of which appears in the Hospital Reports for 1889. Most of the specimens of this disease exhibited at the Pathological Suciety during a period of ten years came under my notice, as well as several others. When collecting materials for an essay on Cancer of the Male Breast based on the records of 100 cases, which was published in THE LANCET of Aug. 10th, 1889. I found recorded, as there mentioned, half-a-dozen examples of duct cancer of the male breast, all of which were published prior to 1888 , with none of which $\mathrm{Mr}$. Bowlby appears to be acquainted. The foregoing and some cases subsequently published are the data on which mp description of the disease in THe LANCET of April 16th, 1892, is based. When Mr. Bowlby has corrected his own work by comparing it with that done by others he will, I think, be in a better position to appreciate the correctness of my classification of the so-called villous duct cancers into simple papillomas and tubular cancers than he now is. At any rate an exhaustive examination of the subject has convinced me that it really is so.

Preston, June 24th, 1898

$$
\text { I am, Sirs, yours faithfully, }
$$

W. ROGER WILLIAMS.

\section{"THE USE OF REPEATED FRACTIONAL DOSES OF CALOMEL."}

\section{To the Editors of THE LANCET.}

SIRs,-I read with pleasure in THE LANCET of July 1st Dr. Chapman's article on the "Use of Repeated Fractional Doses of Calomel " in gastro-intestinal catarrh. For the last few years I have exhibited calomel in a similar manner with gratifying results; but lately I have substituted liquor hydrargyri perchloridi in three minim doses, with, I think, equally favourable results in children, especially when com bined with half-minim doses of ipecacuanha wine. As a rule this combination acts admirably, the vomiting ceasing and the stools rapidly assuming a more normal colour and smell I find children much prefer the mixture to powders, and where medical men do their own dispensing the saving in time is obvious. I am, Sirs, yours truly,

Harrowroad, W., July 18th, 1893. P. GaRdineR, M. B. Glas.

\section{"MEDICAL AID ASSOCIATIONS."}

To the Editors of THE LANCET.

Sirs,-I see that Mr. Clement Sers somewhat misunderstands my position. With respect to the regular clubs, such as the Foresters and Oddfellows, we have no remedy except by declining to serve them. For the most part, however, they were not so much abused and they did not include wires and children. These clubs are now the backbone of medical aid associations and have gone from us. There are left provident dispensaries and private clubs. Provident dispensaries have, or onght to have, a wage limit and a prorision for protest on the part of the medical attendant. Private clubs are in our own hands, as we can make our own rules. In this town I bave initiated a system of provident medical aid which includes all the practitioners as irs staff, and of which I enclose a copy of the rules. I do not pretend that it is a perfect solution of the difficulty; but I think it suggests the way in which this question can be most practically dealt with. I am, Sirs, yours truly, Ioughborough, June 10th, 1893.

J. B. PIKE.

\section{MANCHESTER.}

(FroM OUR OWN CoRRESPONDENT.)

Gorton Servage Works.

THE decision of the Local Government Board has at length been received and the Gorton local board are to spend a large sum of money in the erection of works for the treatment of their own sewage. It was shown at the recent inquiry that this could be done, both more economically and with far less risk of nuisance, by the simple expedient of incorporating outer Gorton with the city of Manchester, of which community it undoubtedly forms a part, although unfortunately it is under separate local government; it appears, however, to be the policy of the Local Govern. ment Board to sanction the perpetuation of petty auto- nomies rather than to bring yressure to bear upon districts like outer Gorton and compel them to join well-equipped and capable authorities like that of Manchester. It is more than probable that when the sewage works come into operation the city corporation may find it necessary to keep a watchful eye on the proccedings of the local board for the protection of the adjoining area of Manchester.

\section{The Iliarrhsea Neason.}

At the close of the week ending July 1st the earth thermometer at a depth of four feet from the surface indicated a temperature of $57.5^{\circ} \mathrm{F}$, and the deaths from diarrhœal diseases during that week numbered 59 , being greatly in excess of the average. In the course of the subsequent fourteen days the four-feet temperature has steadily risen, until, on Saturday last, it attained the unusual height, for the season, of $59 \cdot 3^{\circ}$. The mortality from diarrhoea has increased pari passw with this rise of the earth temperature, the weekly numbers of diarrhceal deaths during the week ending the 8th inst. being 75, and in the week ending on Saturday last no fewer than 87 deaths were recorded, as many as 77 of latter being amongst infants under one year old. The deaths specifically referred in the death certificates to diarrhoa, however, do not appear to represent the whole of the mortality caused by the excessive heat of recent weeks; on the contrary, I find from the official returns that during the last fortnight alone no fewer than 52 additional deaths were attributed to gastro-enteritis or some other disease of a kindred nature to summer diarrhoa, although, of course, these deaths are not returned under the latter heading. The gross death-rate in the city of Manchester during the last fortnight has exceeded 31 per 1000 , although the number of deaths from causes other than diarrhcea has been considerably below the average.

$$
\text { The simall-pox lipidemic. }
$$

The decline in the weekly number of cases of small-pox referred to in my last letter has happily continued throughout the period which has since elapsed, only two or three cases per week having been notified here since the week ending June 24th. Fresh cases, however, continue to be reported in towns which are inconveniently close to Manchester, amongst which Oldham and Chadderton may be mentioned as still apparently suffering considerably from the epidemic. The cases still remaining in the hospitals at Monsall and Clayton Vale are about ejghty in number, not all of which have been sent to hospital from districts within the municipal boundaries. Although the epidemic now seems to be waning in Manchester it is impossible, unless we are to disregard the lessons of previous epidemics, to banish from our minds the strong probability that a recrudescence of small-pox may take place later in the present year, or during the spring of the coming, year. It is to be hoped, therefore, that our city fathers will take care to be preparca for such an event beforehand, so that should a recrudescenee unfortunately take place next spring it may not find us unable to isolate a reasonable number of cases, as was the case at the commencement of the present epidemic. The somewhat expensive teachings of the recent prevalence of small-pox will not have been thrown away if it warns those in authority that the truest economy consists in being always prepared to isolate the first cases of infections sickness and thus to prevent epidemics from making headway amongst the community.

\section{The Jadynell Sanatorium.}

At a recent meeting of the Salford County Council the accounts in convexion with the Ladywell Sanatorium were discussed. It appears that the total cost of the buildings, land \&c is between $\$ 65,000$ and $£ 70,000$, or something like $£ 300$ per bed. At the time when the hospital was opened for the reception of patients a favourable opinion as to its general arrangements and adaptability for the purposes of an establishment for the isolation of infeetious diseases was expressed in these columns. The experi. ence gained since the opening of the hospital only tends to confirm the good opinion formed on that occasion. It is, perhaps, not too much to say that amongst the many well-equipped and well-planned large fever hospitals whicb have been constructed in the provinces within the last. ten years there is, perhaps, not one which can be re.. garded as being superior to the Ladywell Sanatorium. It will be remembered that this institution is intended for the isolation. of cases of fever only, a clause having been agreed to by the corporation the effect of which will be to prevent the future. 